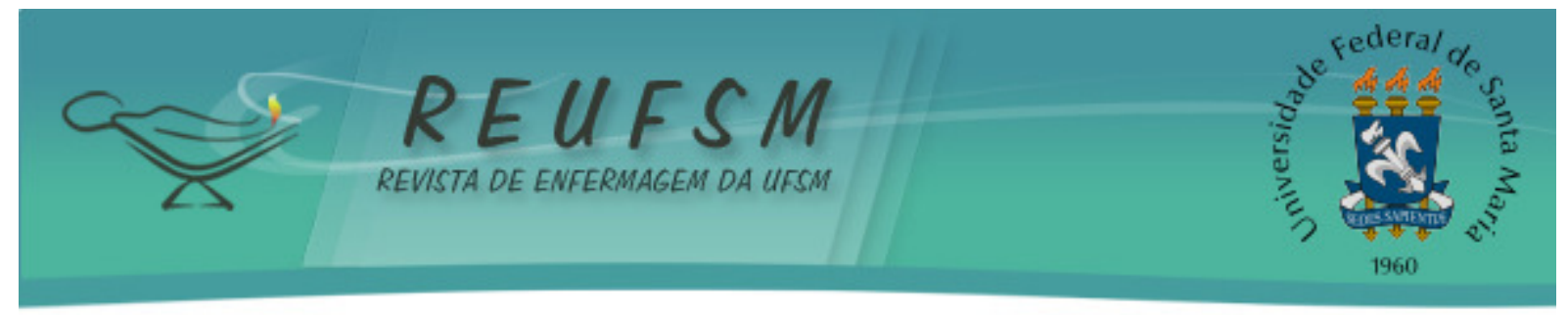

\title{
PRÁTICAS SEXUAIS, USO DO PRESERVATIVO E TESTAGEM PARA O HIV ENTRE GRADUANDOS DE ENFERMAGEM
}

\section{SEXUAL PRACTICES, CONDOM USE AND HIV TESTING AMONG NURSING UNDERGRADUATES}

\section{PRÁCTICAS SEXUALES, USO DE CONDONES Y PRUEBA PARA EL VIH ENTRE LOS GRADUANDOS DE ENFERMERÍA}

\author{
Thelma Spindola ${ }^{1}$ \\ Vinícius Rodrigues Fernandes da Fonte ${ }^{2}$ \\ Elizabeth Rose Costa Martins ${ }^{3}$ \\ Márcio Tadeu Ribeiro Francisco ${ }^{4}$ \\ Carolina Passos Sodré 5 \\ Claudia Silvia Rocha Oliveira ${ }^{6}$
}

\section{Doi: $10.5902 / 2179769225736$}

Resumo: Objetivo: identificar as práticas sexuais, o uso do preservativo e a realização do teste diagnóstico para infecção pelo human immunodeficiency virus (HIV) entre graduandos de enfermagem. Método: estudo descritivo com abordagem quantitativa e amostra por conveniência. O cenário foram duas instituições de ensino superior localizadas no município do Rio de Janeiro, Brasil. Os participantes foram 250 graduandos de enfermagem. A coleta de dados foi realizada com auxílio de um questionário, durante os meses de abril de 2013 a abril de 2014. Os dados foram analisados por meio da estatística descritiva. Resultados: 73,6\% dos participantes relataram ter relações sexuais, 58,2\% fazem sexo de forma segura sempre, $50,6 \%$ utilizam preservativos em relações estáveis, $89,1 \%$ usam preservativos com parceiros(as) casuais e 44,8\% realizaram o teste diagnóstico para HIV. Conclusão: é preciso investir em educação em saúde junto aos graduandos de enfermagem para que adotem condutas sexuais preventivas frente ao HIV.

Descritores: Comportamento sexual; Preservativos; Doenças sexualmente transmissíveis; HIV; Enfermagem.

ABSTRACT: Aim: to identify sexual practices, condom use and the realization of diagnostic test for human immunodeficiency virus (HIV) infection among nursing students. Method:

\footnotetext{
${ }^{1}$ Enfermeira. Doutora em Enfermagem pela Universidade Federal do Rio de Janeiro. Professora Associada da Faculdade de Enfermagem da Universidade do Estado do Rio de Janeiro, Rio de Janeiro, Brasil, tspindola.uerj@gmail.com.

${ }^{2}$ Enfermeiro. Mestre em Enfermagem pela Universidade do Estado do Rio de Janeiro. Enfermeiro da Secretaria Municipal de Saúde do Rio de Janeiro, Rio de Janeiro, Brasil, vinicius-fonte@ hotmail.com.

${ }^{3}$ Enfermeira. Doutora em Enfermagem pela Universidade Federal do Rio de Janeiro. Professora Adjunta da Faculdade de Enfermagem da Universidade do Estado do Rio de Janeiro e do Curso de Graduação em Enfermagem da Universidade Veiga de Almeida, Rio de Janeiro, Brasil, oigresrose@uol.com.br.

${ }^{4}$ Enfermeiro. Doutor em Saúde Coletiva pela Universidade do Estado do Rio de Janeiro. Professor Associado da Faculdade de Enfermagem da Universidade do Estado do Rio de Janeiro e Coordenador do Curso de Graduação em Enfermagem da Universidade Veiga de Almeida, Rio de Janeiro, Brasil, mtadeu@uva.br.

5 Graduanda em Enfermagem pela Universidade do Estado do Rio de Janeiro, Rio de Janeiro, Brasil, c.sodrepassos@gmail.com.

${ }^{6}$ Graduanda em Enfermagem pela Universidade do Estado do Rio de Janeiro, Rio de Janeiro, Brasil, claudiaoliveira@oi.com.br.
} 


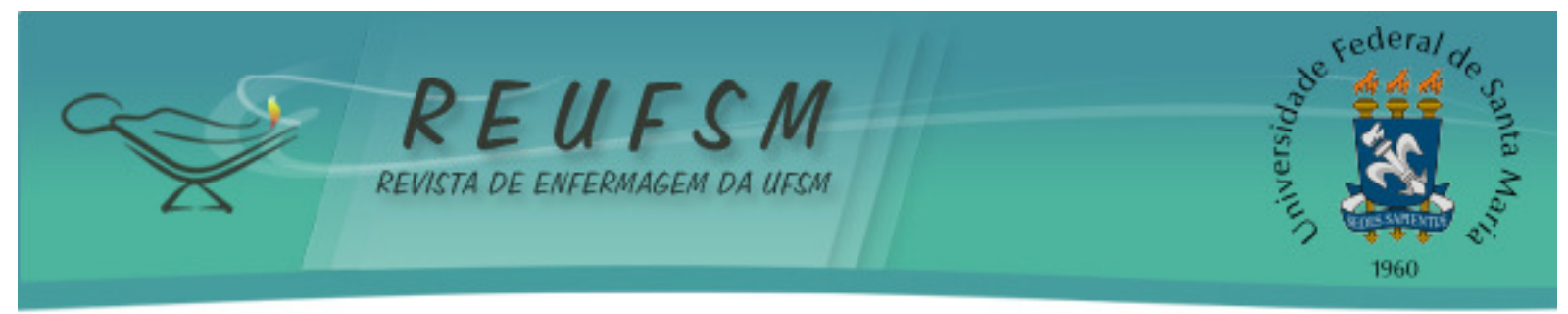

descriptive study with quantitative approach and sample for convenience. The scenario was two college institutions located in the city of Rio de Janeiro, Brazil. The participants were 250 nursing students. Data collection was performed with the help of a questionnaire during the months of April 2013, to April 2014. Data were analyzed through descriptive statistics. Results: $73,6 \%$ of the participants reported having sex, 58,2\% always have safe sex, 50,6\% use condoms in stable relationships, $89,1 \%$ use condoms with casual partners, and 44,8\% did the HIV diagnostic test. Conclusion: it is necessary to invest in health education with nursing undergraduates to adopt preventive sexual behaviors against HIV.

Descriptors: Sexual Behavior; Condoms; Sexually transmitted diseases; HIV; Nursing.

RESUMEN: Objetivo: identificar las prácticas sexuales, uso del condón y prueba de diagnóstico para la infección por el virus de la inmunodeficiencia humana (VIH) entre estudiantes de enfermería. Método: estúdio descriptivo, cuantitativo y de muestra por conveniencia. El escenario fue dos centros de enseñanza superior en el municipio de Rio de Janeiro, Brazil. Los participantes fueron 250 estudiantes de enfermería. La recolección de datos se realizó a partir de un cuestionario, durante el período de abril de 2013 a abril de 2014. Los datos fueron analizados por estadística descriptiva. Resultados: 73,6\% de los participantes reportaron tener relaciones sexuales, 58,2\% tienen sexo de forma segura siempre, 50,6\% utilizan preservativos en relaciones estables, $89,1 \%$ usan preservativos con parejas casuales y 44,8\% realizaron la prueba diagnóstica para el VIH. Conclusión: es necesario invertir en educación de salud con los graduandos de enfermería para que adopten conductas sexuales preventivas del VIH.

Descriptores: Conducta Sexual; Condones; Enfermedades de transmisión sexual; VIH; Enfermería.

\section{INTRODUÇÃO}

As infecções sexualmente transmissíveis (IST) prevalecem como um importante desafio para saúde pública mundial. A Organização Mundial da Saúde estima que, a cada ano, 500 milhões de pessoas adoecem devido às IST curáveis, como clamídia, gonorreia, sífilis e tricomoníase. A incidência de novas infecções no mundo pode chegar a 360 milhões de casos/ano, sendo de 10 a 12 milhões apenas no Brasil. ${ }^{1}$ No que tange à infecção pelo human immunodeficiency virus (HIV) e acquired immunodeficiency syndrome (aids), estimativa do Programa Conjunto das Nações Unidas sobre o HIV/aids (UNAIDS) aponta que existem cerca de 35 milhões de pessoas que vivem com HIV/aids (PVHA) no mundo, sendo 2,7 milhões de novas infecções em 2010, das quais $42 \%$ ocorreram em jovens entre 15 e 24 anos. ${ }^{2}$

A dinâmica epidemiológica das IST, na sociedade, abarca uma multiplicidade de fatores de origem comportamental, social, político, tecnológico e programático que condicionam situações de vulnerabilidades aos indivíduos ou grupos populacionais, que partilham de características em comum. Estudos ${ }^{3-4}$ apontam que a população de jovens universitários possui elevado risco às IST, uma vez que estão iniciando a vida sexual e mudando frequentemente de 


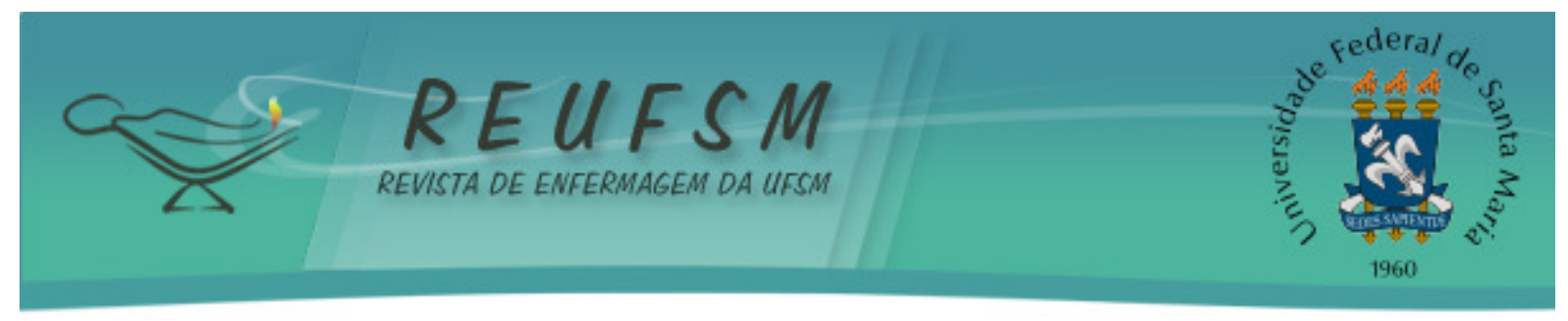

parceiros. A vida universitária favorece o aparecimento e consolidação de determinados comportamentos, especialmente relacionados ao consumo de álcool e outras drogas e práticas sexuais desprotegidas. Dados indicam que o consumo de substâncias psicoativas entre os universitários é mais frequente do que na população em geral, e o seu uso aumenta a probabilidade de viver uma situação de risco, dentre elas, o sexo sem proteção. ${ }^{3-4}$

No que concerne ao conhecimento dos universitários sobre a importância do uso do preservativo na prevenção de IST, investigações têm demonstrado que o alto nível de escolaridade não implica, necessariamente, em maior conhecimento sobre as formas de transmissão e prevenção das IST e na adoção de práticas sexuais seguras. ${ }^{5-6}$ Não obstante, os universitários que são um grupo formado, geralmente, por adultos jovens, sofrem pela vulnerabilidade programática. No Brasil, os universitários ainda carecem de um programa de saúde voltado para suas necessidades, assim como o já existente programa de saúde nas escolas. Contudo, é sabido que as atividades de educação sexual nas escolas ainda não são praticadas ou permitidas em muitas culturas, que preferem não discutir a vida sexual das pessoas, legitimando concepções morais retrógadas, sendo assim, os jovens adentram na vida universitária sem informações pertinentes à saúde sexual.

Os serviços de saúde pública são constantemente desafiados a (re)pensar estratégias de cuidado que incluam os jovens em suas atividades, pois se trata de uma população volátil e culturalmente desvinculada, e os atendimentos são realizados de forma pontual e fragmentada. Os profissionais, nem sempre, estão adequadamente capacitados e/ou preparados para lidar com essa população e suas demandas. ${ }^{7}$

O impacto, dinamismo e a multicausalidade das IST na população jovem justifica a realização deste estudo, que estabelece como problema de pesquisa: os graduandos de enfermagem adotam práticas sexuais preventivas, fazem uso do preservativo e realizam teste diagnóstico para o HIV? Delimitou-se, então, o seguinte objetivo para a investigação: identificar as práticas sexuais, o uso do preservativo e a realização do teste diagnóstico para o HIV entre graduandos de enfermagem.

\section{MÉTODO}




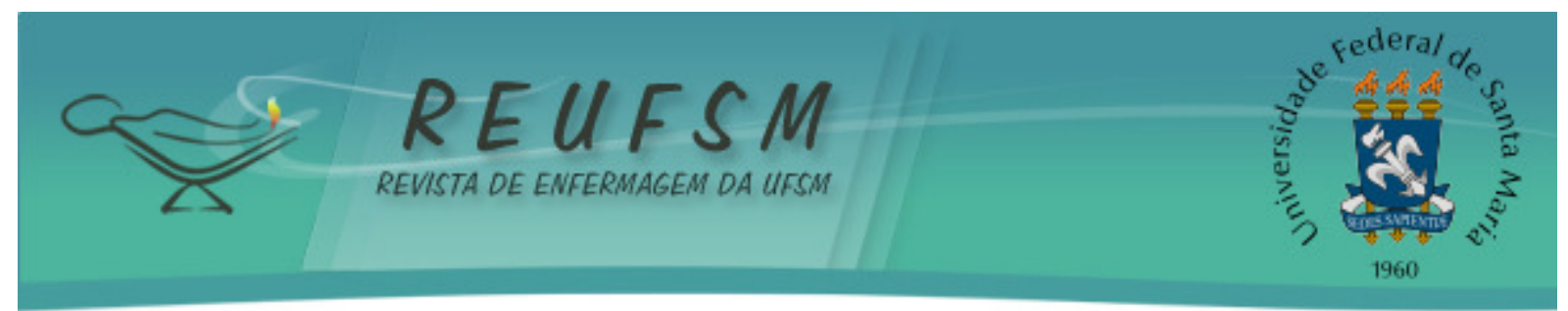

Trata-se de um estudo, fruto do projeto de extensão intitulado "Quando o assunto é prevenção: dialogando com jovens acerca das doenças sexualmente transmissíveis". O projeto tem como proposta fazer com que os jovens universitários reflitam sobre o comportamento sexual e os riscos a que estão expostos quando praticam sexo inseguro.

Esta investigação ocorreu por meio das primeiras ações do projeto, assim que foi criado pela Faculdade de Enfermagem da Universidade do Estado do Rio de Janeiro. Inicialmente, a coordenadora do projeto teve dificuldade de acessar os coordenadores das diversas unidades acadêmicas para sensibilização quanto ao projeto, de modo a garantir a entrada das ações extensionistas nas diversas faculdades e cursos que compõem a instituição. Nesse sentido, as ações se resumiam nas áreas de convivência dos Campus Universitários, sem uma atividade mais próxima e estimulada pelos coordenadores das unidades acadêmicas.

Com o apoio da direção da Faculdade de Enfermagem foi possível iniciar, para além das atividades de extensão, as atividades de pesquisa com intuito de contribuir ao enfrentamento às IST/HIV/aids entre os universitários, nesse caso, os graduandos de enfermagem. Sendo assim, foi aplicado o método descritivo e a abordagem quantitativa. O cenário do estudo foram duas instituições de ensino superior, uma pública e outra privada, localizadas no Município do Rio de Janeiro. Tendo em vista, que as ações na Faculdade de Enfermagem mobilizaram professores que atuavam concomitantemente em uma instituição privada, de modo a obter o apoio para realização das atividades de extensão nesta outra instituição.

Foram considerados elegíveis para o estudo os graduandos de enfermagem com matrícula ativa e com idade igual ou superior a 18 anos. Como critérios de exclusão estabeleceu-se a deficiência sensorial (visual), pois não foi adaptado um questionário em braile, e participação no pré-teste. A população foi composta por 900 graduandos de enfermagem de ambas as instituições (pública e privada).

A população foi composta por 900 graduandos de enfermagem de ambas as instituições (pública e privada). Foi adotada a amostra por conveniência, tendo em vista que a seleção dos participantes do estudo envolvia as instituições onde eram realizadas as ações do projeto de extensão, obtendo-se a participação de 250 graduandos de enfermagem.

A coleta de dados foi realizada por seis bolsistas do projeto, antes do desenvolvimento das atividades de extensão. O Instrumento de Coleta de Dados (ICD) utilizado foi um questionário contendo 50 perguntas. Sua elaboração teve como alicerce a "Pesquisa de conhecimentos, atitudes 


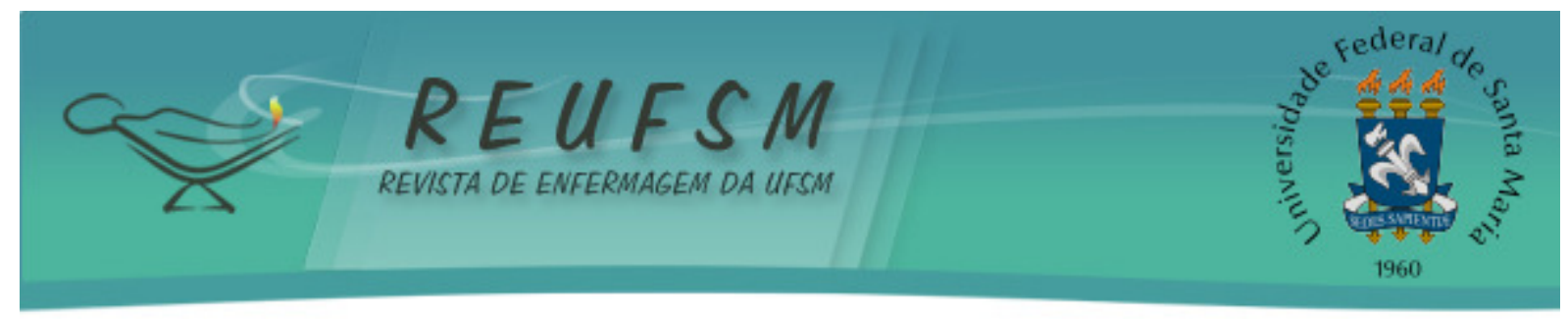

e práticas na população brasileira", realizada em 2008 pelo Ministério da Saúde do Brasil. Para atender aos objetivos do estudo foram selecionadas variáveis relacionadas ao perfil socioeconômico, práticas sexuais, o uso do preservativo e testagem para o HIV. ${ }^{8}$

$\mathrm{O}$ instrumento foi testado quanto a sua efetividade, sendo aplicado um pré-teste com 10 graduandos de enfermagem da instituição pública. Os questionários utilizados para o préteste foram descartados e os graduandos participantes adentraram no critério de exclusão do estudo. O tempo de preenchimento, em média, para responder o ICD foi de 20 minutos. A pesquisa foi realizada entre os meses de abril de 2013 a abril de 2014, sendo iniciada em abril de 2013 na Universidade Pública e, posteriormente, na universidade privada.

A abordagem aos participantes do estudo foi realizada por meio de divulgação com cartazes, nas respectivas instituições e com a ajuda dos professores. Em geral, a aplicação dos questionários era realizada nas salas, após as aulas. Em outras ocasiões, foram realizadas abordagens nas dependências das instituições ou combinados horários com os graduandos que se mostravam interessados em participar. A privacidade e o conforto para a realização da pesquisa eram prioridade, sendo as coletas realizadas em salas com iluminação, conforto térmico, cadeira e mesa. Os dados foram tabulados e organizados pela aplicação da estatística descritiva, em frequência absoluta e percentual, com auxílio do Microsoft Excel 2007.

Para o desenvolvimento desta investigação, foram respeitadas as normas da Resolução 466/2012 do Conselho Nacional de Saúde, Ministério da Saúde, Brasil, que regulamenta as pesquisas realizadas com seres humanos. O projeto de pesquisa foi aprovado pelo Comitê de Ética em Pesquisa (CEP) da Universidade privada, sob o parecer de número 327.872, em 06 de julho de 2013 e pelo CEP da Universidade pública, sob o número 063.2012, em 18 de setembro de 2012. Todos os participantes do estudo foram esclarecidos quanto aos objetivos da pesquisa, concordaram em participar e assinaram o Termo de Consentimento Livre e Esclarecido.

\section{RESULTADOS}

Participaram da pesquisa 250 acadêmicos de enfermagem, 135 provenientes de uma universidade pública e 115 de uma privada, situadas no Município do Rio de Janeiro. As características socioeconômicas dos participantes são descritas na tabela 1, que evidencia o predomínio de participantes do sexo feminino, jovens, com a cor da pele parda, solteiros(as), de religião católica, com renda familiar entre três a cinco salários mínimos (SM) e sem filhos. A maioria ainda vive com os pais. 


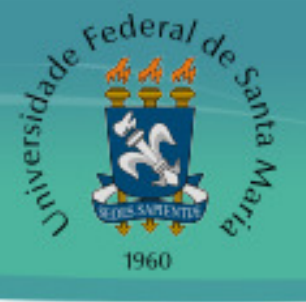

Tabela 1 - Perfil socioeconômico de graduandos de enfermagem de duas Universidades no Rio de Janeiro (Brasil). Rio de Janeiro, 2014. ( $\mathrm{N}=250)$

\begin{tabular}{|c|c|c|}
\hline Perfil Social & $\mathrm{f}$ & $\%$ \\
\hline \multicolumn{3}{|l|}{ 1. Sexo } \\
\hline Feminino & 217 & 86,8 \\
\hline Masculino & 33 & 13,2 \\
\hline \multicolumn{3}{|l|}{ 2. Faixa etária } \\
\hline 18 a 21 & 132 & 52,8 \\
\hline 22 a 25 & 70 & 28,0 \\
\hline 26 a 29 & 17 & 6,8 \\
\hline 30 ou mais & 31 & 12,4 \\
\hline \multicolumn{3}{|l|}{ 3. Cor da pele } \\
\hline Amarela & 4 & 1,6 \\
\hline Branca & 100 & 40,0 \\
\hline Preta & 21 & 8,4 \\
\hline Parda & 116 & 46,4 \\
\hline Não sabe & 6 & 2,4 \\
\hline Não informou & 3 & 1,2 \\
\hline \multicolumn{3}{|l|}{ 4. Situação conjugal } \\
\hline Possui parceiro(a) fixo(a) & 83 & 33,2 \\
\hline Não possui parceiro(a) fixo(a) & 130 & 52,0 \\
\hline Não respondeu & 37 & 14,8 \\
\hline \multicolumn{3}{|l|}{ 5. Possui filhos } \\
\hline Sim & 20 & 8,0 \\
\hline Não & 227 & 90,8 \\
\hline Não respondeu & 3 & 1,2 \\
\hline \multicolumn{3}{|l|}{ 6. Renda familiar } \\
\hline Menor que $1 \mathrm{SM}$ & 5 & 2,0 \\
\hline De 1 a 2 SM & 66 & 26,4 \\
\hline De 3 a 5 SM & 84 & 33,6 \\
\hline De 6 a 7 SM & 16 & 6,4 \\
\hline Maior que $7 \mathrm{SM}$ & 36 & 14,4 \\
\hline Não sabe & 5 & 2,0 \\
\hline Não informou & 38 & 15,2 \\
\hline \multicolumn{3}{|l|}{ 7. Religião } \\
\hline Católica & 97 & 38,8 \\
\hline Espírita & 29 & 11,6 \\
\hline Protestante (evangélico) & 67 & 26,8 \\
\hline Outras & 7 & 2,8 \\
\hline Não possui religião & 46 & 18,4 \\
\hline Não informou & 4 & 1,6 \\
\hline TOTAL & 250 & 100 \\
\hline
\end{tabular}

Fonte: elaborado pelos autores.

SM: Salário mínimo (R \$ 724,00, em 2014). 


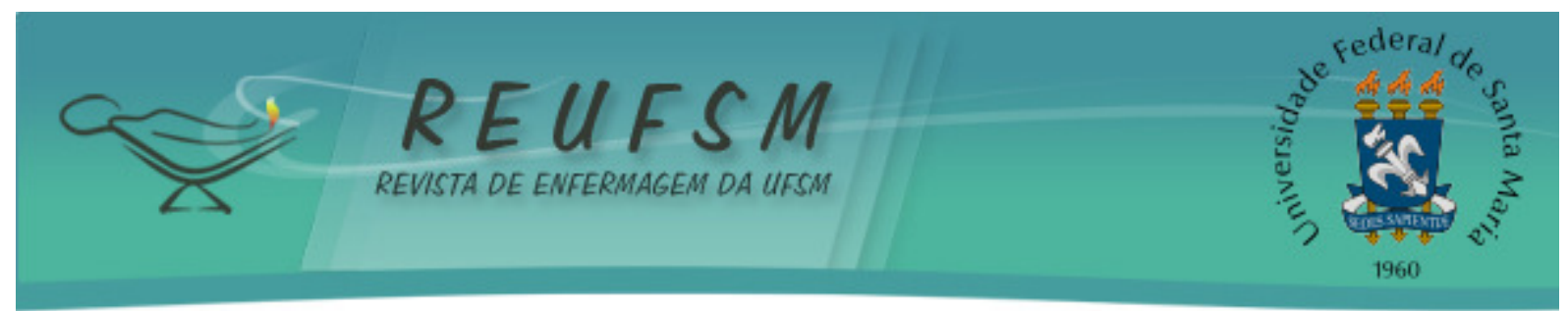

Em relação às práticas sexuais, evidenciados na tabela 2, a maioria dos participantes têm vida sexual ativa, e a primeira relação ocorreu ainda na adolescência. O preservativo não é utilizado em todas as relações sexuais, apesar de a maioria informar utilizá-lo sempre. As relações sexuais ocorrem, em geral, com parceiros estáveis/fixos(as), contudo o preservativo é mais utilizado com os parceiros casuais.

Tabela 2 - Práticas sexuais e realização de teste diagnóstico para o HIV entre graduandos de enfermagem de duas Universidades no Rio de Janeiro (Brasil). Rio de Janeiro, 2014. (N=250)

\begin{tabular}{|c|c|c|}
\hline Práticas sexuais e teste diagnóstico para o HIV & $\mathrm{N}$ & $\%$ \\
\hline \multicolumn{3}{|l|}{ 1. Já teve relações sexuais } \\
\hline Sim & 184 & 73,6 \\
\hline Não & 66 & 26,4 \\
\hline \multicolumn{3}{|l|}{ 2. Primeira relação sexual* } \\
\hline 12 a 14 anos & 41 & 22,3 \\
\hline 15 a 18 anos & 92 & 50,0 \\
\hline 19 a 21 anos & 39 & 21,2 \\
\hline Acima de 22 anos & 11 & 6,0 \\
\hline Não relatou & 1 & 0,5 \\
\hline \multicolumn{3}{|l|}{ 3. Pratica sexo de forma segura sempre?* } \\
\hline Sim & 107 & 58,2 \\
\hline Não & 77 & 41,8 \\
\hline \multicolumn{3}{|l|}{ 4. Usou preservativo na primeira relação?* } \\
\hline Sim & 112 & 60,9 \\
\hline Não & 70 & 38,0 \\
\hline Não respondeu & 2 & 1,1 \\
\hline \multicolumn{3}{|c|}{ 5. Já teve relação sexual com mais de 5 parceiros(as) casuais na sua vida?* } \\
\hline Sim & 10 & 5,4 \\
\hline Não & 152 & 82,6 \\
\hline Não relatou & 22 & 12,0 \\
\hline \multicolumn{3}{|c|}{ 6. Já teve relações sexuais com pessoas do mesmo sexo que o seu?** } \\
\hline Sim & 17 & 9,2 \\
\hline Não & 167 & 90,8 \\
\hline \multicolumn{3}{|c|}{ 7. Já teve relação sexual com pessoa que conheceu pela internet?* } \\
\hline Sim & 14 & 7,6 \\
\hline Não & 165 & 89,7 \\
\hline Não relatou & 5 & 2,7 \\
\hline \multicolumn{3}{|c|}{ 8. Nas relações sexuais com parceiro(a) fixo(a) usou preservativo? $\dagger$} \\
\hline Sim & 80 & 50,6 \\
\hline Não & 69 & 43,7 \\
\hline Não relatou & 9 & 5,7 \\
\hline \multicolumn{3}{|c|}{ 9. Nas relações sexuais com parceiro(a) casual usou preservativo? $\ddagger$} \\
\hline Sim & 41 & 89,1 \\
\hline Não & 5 & 10,9 \\
\hline \multicolumn{3}{|l|}{ 10. Realizou testagem diagnóstica para o HIV? } \\
\hline Sim & 112 & 44,8 \\
\hline
\end{tabular}




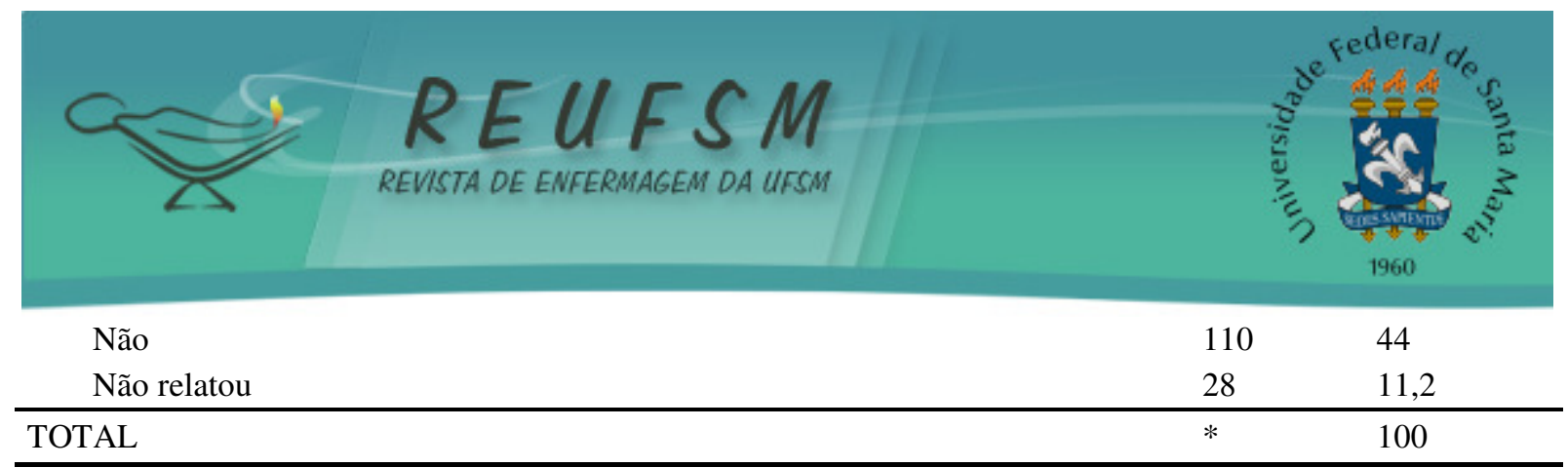

Fonte: elaborado pelos autores.

*Foram contabilizados apenas os participantes que iniciaram vida sexual

$\dagger$ Apenas 158 participantes tiveram prática sexual com parceiro fixo

†Apenas 46 participantes tiveram prática sexual com parceiro casual

Indagados sobre o uso do preservativo feminino, apenas $16(8,7 \%)$ dos universitários afirmou ter utilizado alguma vez na vida, enquanto que $168(91,3 \%)$ nunca o experimentaram. Quanto à realização de testagem para detecção do HIV apenas 44,8\% fizeram o teste.

\section{DISCUSSÃO}

A predominância de participantes do sexo feminino é uma característica dos cursos de graduação em enfermagem, sendo um aspecto associado à história da profissão. Apesar do aumento do quantitativo de graduandos do sexo masculino, a profissão ainda é marcada por questões culturais e simbólicas que remetem ao trabalho feminino. ${ }^{9-10}$

No que tange à faixa etária, é inegável a quantidade de jovens que participaram do estudo. A população universitária, em geral, é constituída por jovens, que após concluírem o ensino médio, prosseguem estudando por meio do ensino superior para especialização profissional e científica. A universidade tem um papel formador, não apenas no aspecto profissional e científico, mas na construção da vida social. O ambiente propicia inúmeras experiências antes proibidas ou limitadas no convívio familiar; fomenta cada vez mais a liberdade; propicia vivências de romances e responsabilidades; aumenta a rede social; incita a participação em festas e eventos, nos quais, às vezes, é estimulado o consumo de bebidas alcoólicas e/ou outras drogas. ${ }^{3,6,11-12} \mathrm{O}$ ambiente universitário, associado aos aspectos biopsicossocioculturais da juventude, têm sido apontado em estudos como um espaço suscetível a ocorrência de problemas de saúde, como o consumo de bebidas alcoólicas, uso de tabaco e/ou drogas ilícitas, gravidez indesejada ou não planejada e a ocorrência de IST. ${ }^{13-14}$

No que tange às práticas sexuais, os jovens universitários possuem baixa percepção de risco e não se consideram vulneráveis aos problemas de saúde. Não obstante, as características de gênero acentuam essa gravidade ao legitimar a liberdade sexual entre os homens e a passividade e dominação masculina entre as mulheres. ${ }^{5,9,11,15}$

Pesquisa realizada com 351 graduandos da área da saúde, identificou que o preservativo não foi utilizado por $48,7 \%$ dos entrevistados nas últimas relações sexuais e $37 \%$ 


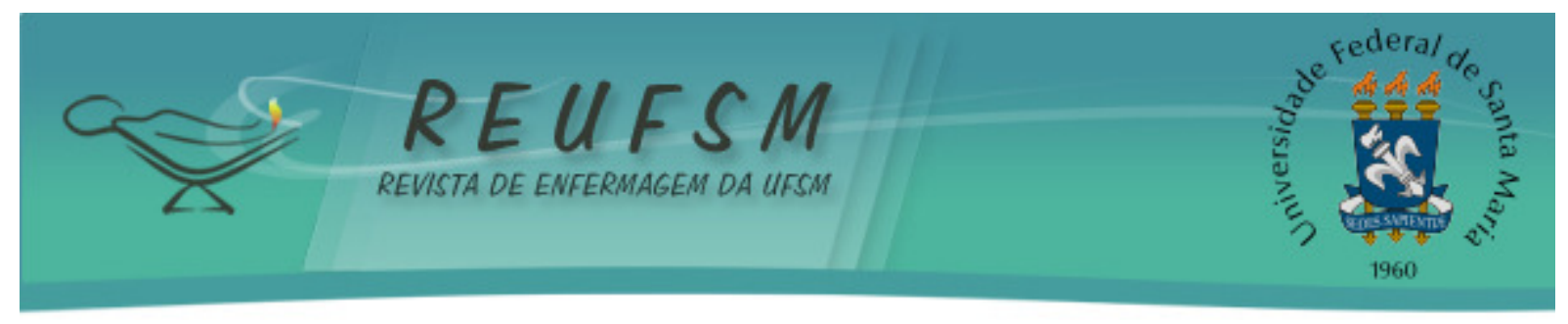

tiveram entre três a dez parceiros nos últimos 12 meses, dados esses estatisticamente significativos com a variável de consumo alcoólico. ${ }^{16}$ Investigação no interior de Minas Gerais (Brasil), com 786 acadêmicos de cursos da área da saúde, apontou que 88,2\% dos participantes já haviam tido relações sexuais, 47,9\% possuíam parceiros fixos e, apenas, 19,5\% faziam uso regular do preservativo. Para o gênero feminino, foi estatisticamente significativa à presença de parceiro fixo com a não utilização do preservativo na última relação. Enquanto que o uso do preservativo na última relação sexual foi associado significativamente aos universitários que não tinham religião e moravam com amigos. ${ }^{11}$

Na cidade de Fortaleza, no Brasil, pesquisa com 161 jovens universitários de cursos da área da saúde, com idades entre 18 a 25 anos, demonstrou que 63,3\% já iniciaram vida sexual; $80 \%$ nunca realizaram teste para detecção do HIV; 33,3\% utilizam o preservativo sempre; $75,7 \%$ têm como principal forma de aquisição dos preservativos as farmácias e 60,9\% se consideram com baixo risco para contrair o HIV. Os principais fatores para o abandono do uso da camisinha na primeira e última relação sexual foram confiança no parceiro e uso de anticoncepcional, respectivamente. ${ }^{9}$

Pesquisas com jovens universitários colombianos observaram que os graduandos, em sua maioria, são solteiros; $51,2 \%$ dos participantes referiram ter utilizado o preservativo na primeira relação sexual, enquanto que apenas $25 \%$ utilizam em todas as relações sexuais; os homens são significativamente mais propensos a manter relações extraconjugais; e a gravidez foi referida por 8,5\% dos universitários, sendo que 79,5\% não desejaram e 7\% dessas relações ocorreram sob o efeito de álcool; a prevalência de aborto foi de 6,7\%, dos quais 47,2\% foram induzidos. Quanto às IST, 2,8\% afirmaram ter recebido, ao menos, um diagnóstico, sendo estatisticamente associado a mulheres e graduandos dos últimos semestres dos cursos de universitários. ${ }^{3,15,17}$

Os estudos apresentados na discussão dessa investigação tiveram como participantes os universitários. Nessa pesquisa, apenas os graduandos de enfermagem foram incluídos. Assim, por ser um grupo predominantemente feminino, as implicações referentes às questões de gênero puderam ser melhor observadas, como a pouca variabilidade de parceiros e a predominância de práticas sexuais com parceiros fixos.

Contudo, o estudo corrobora com as demais investigações, ao constatar que os jovens têm iniciado a vida sexual cada vez mais cedo, com múltiplos parceiros, uso inconsistente do preservativo, principalmente o feminino e baixa percepção de risco para IST..$^{3,5,9,11,15-17}$ Estudo 


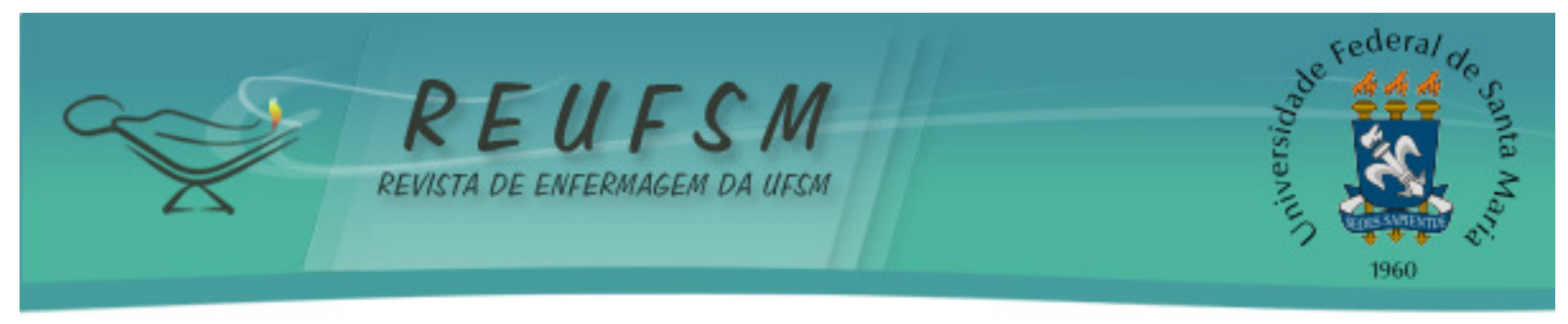

transversal, realizado na Colômbia com a participação de 934 universitários, revela que os jovens possuem múltiplos parceiros (as), baixa adesão quanto a realização de testes sorológicos para detecção de IST e consumo de álcool e outras drogas. A repercussão dos comportamentos sexuais de risco acarretou gravidez não planejada para $12 \%$ da amostra; apenas 11,8\% realizaram prova sorológica para o HIV e 1,9\% afirmaram ter tido algum caso de IST. ${ }^{4}$

Pesquisa qualitativa envolvendo 67 universitários colombianos constatou que a população reconhece o preservativo como um método preventivo eficaz. Entretanto, o seu uso provoca incômodo e insatisfação, além de gerar desconfiança entre os/as parceiros (as). ${ }^{18}$

Em pesquisa realizada com 380 graduandos de enfermagem de uma Universidade Colombiana, foi evidenciado que, apesar de serem alunos da área da saúde e estarem em formação para prestação de cuidados ao indivíduo e a sociedade, ainda assim suas condutas e comportamentos estão condicionados a estilos de vida inadequados, que os expõem a situações de risco para o desenvolvimento de problemas de saúde. Já durante a formação, esses alunos são confrontados a lidar com o conhecimento sobre hábitos de vida saudáveis e sua aplicabilidade na prática de sua profissão e na sua vida cotidiana. $\mathrm{O}$ estudo aponta que a mudança de comportamento é um processo longo, mas que as universidades representam um espaço de oportunidades para promoção do desenvolvimento do potencial máximo de saúde. ${ }^{19}$

Em relação ao teste diagnóstico para o HIV, os resultados desse estudo evidenciam o distanciamento da meta 90-90-90, proposta pelo UNAIDS, o qual prevê que 90\% das pessoas conheçam sua sorologia para o HIV, 90\% das pessoas com diagnóstico de HIV estejam em tratamento e que $90 \%$ das pessoas em tratamento tenham carga viral indetectável. ${ }^{20}$

\section{CONCLUSÃO}

Os achados demonstram que a maioria dos graduandos de enfermagem, semelhante a outros jovens, iniciou as atividades sexuais na adolescência. Existe um quantitativo expressivo de jovens que não adota o preservativo de maneira contínua. Pouco mais da metade dos participantes faz uso regular do preservativo em seus relacionamentos. Existe prevalência de jovens que vivem relacionamentos estáveis e não adotam o preservativo com esses parceiros. Contudo, entre os graduandos que tiveram relacionamentos com parceiros eventuais a maioria fez uso do preservativo. 


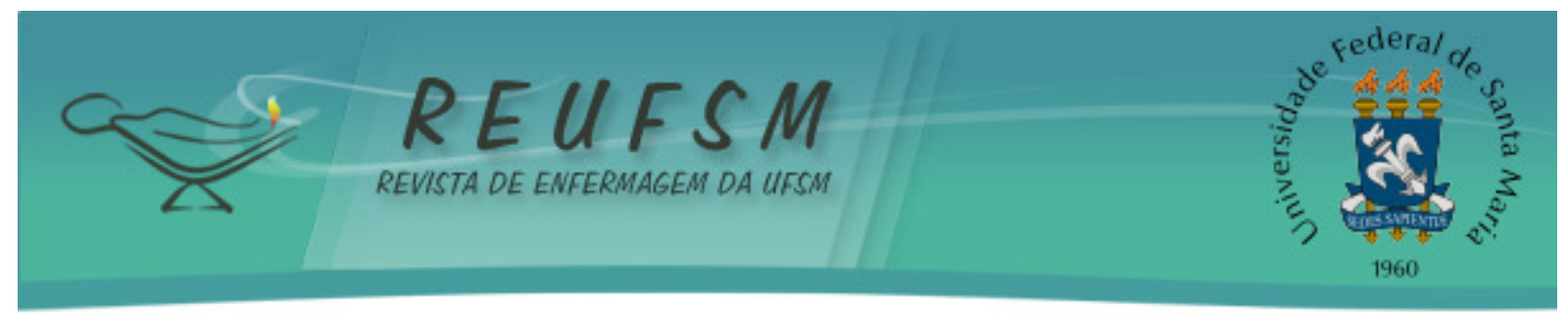

Embora os graduandos tenham um comportamento de risco para adquirir uma IST, menos da metade realizou alguma vez o teste diagnóstico para o HIV, sendo uma prática pouco comum no conjunto amostral investigado. Essa investigação teve como limitação ter sido realizada apenas com graduandos de enfermagem em instituições, que até então, não possuíam atividades de extensão para as IST/HIV/aids com foco nos universitários. Nesse sentido, algumas práticas sexuais e baixa realização da testagem podem estar associadas com ausência de ações de educação em saúde.

Por outro lado, os resultados alcançados com os graduandos de enfermagem e as ações do projeto nas áreas de convivência dos Campus, propiciaram o contato com os diretores e coordenadores das unidades acadêmicas para realização das atividades extensionistas. O projeto segue suas atividades, com o intuito de envolver jovens universitários de áreas de conhecimento distintas, para que se possa (re)pensar estratégias e políticas de saúde voltadas para o cuidado desse grupo.

Essa investigação ainda apresenta algumas lacunas que outros estudos poderiam contribuir para um maior aprofundamento na temática, como no caso dos preservativos masculinos e femininos. Nesse estudo, o objetivo não era saber qual modelo de preservativo era utilizado ou mais utilizado, mas se o jovem usava o preservativo. Sendo assim, foi feita apenas uma pergunta para saber se os jovens usam o preservativo feminino, tendo em vista que o consumo do masculino ainda é predominante no país. Considerando a feminização da epidemia de HIV, as relações desiguais entre gêneros e o acesso gratuito ao preservativo feminino nas unidades de saúde, é oportuno à condução de estudos sobre a temática.

\section{REFERÊNCIAS}

1. Carvalho PMRS, Guimarães RA, Moraes PA, Teles SA, Matos MA. Prevalence of signs and symptoms and knowledge about sexually transmitted diseases. Acta Paul Enferm [Internet]. 2015 fev [acesso em 2016 set 26];28(1):95-100. Disponivel em: http://www.scielo.br/scielo.php?script=sci_arttext\&pid=S0103-

$21002015000100095 \& \operatorname{lng}=$ en\&nrm=iso\&tlng=en.

2. Joint United Nations Programe on HIV/AIDS (UNAIDS). Global report: UNAIDS report on the global AIDS epidemic 2013. Geneva: UNAIDS; 2013. 198 p.

3. Díaz-Cárdenas S, Arrieta-Vergara K, González-Martínez F. Prevalencia de actividad sexual y resultados no deseados em salud sexual y reproductiva en estudiantes universitarios em Cartagena, Colombia, 2012. Rev Colomb Obstet Ginecol [Internet]. 2014 [acesso em 2016 set 26];65(1):22-31. Disponivel em http://www.scielo.org.co/pdf/rcog/v65n1/v65n1a04.pdf. 


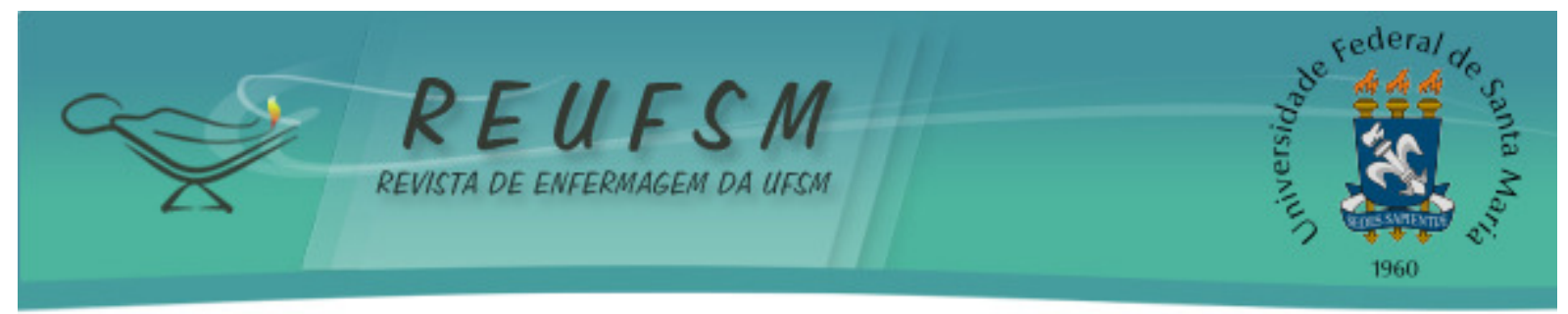

4. Gómez-Camargo DE, Ochoa-Diaz MM, Canchila-Barrios CA, Ramos-Clason EC, Salguedo-Madrid GI, Malambo-García DI. Salud sexual y reproductiva em estudiantes universitários de uma instituición de educación superior en Colombia. Rev Salud Pública [Internet]. 2014 [acesso em 2016 set 26];16(5):670-82. Disponível em: http://www.redalyc.org/articulo.oa?id=42239149003.

5. Dessunti EM, Reis AOA. Vulnerabilidade às DST/aids entre estudantes da saúde: estudo comparativo entre primeira e última série. Ciênc Cuid Saúde [Internet]. 2012 [acesso em 2016 set 26];11(Supl):274-83. Disponível em: http://www.periodicos.uem.br/ojs/index.php/CiencCuidSaude/article/view/17738/pdf.

6. Castro EL, Caldas TA, Morcillo AM, Pereira EMA, Velho PENF. O conhecimento e o ensino sobre doenças sexualmente transmissíveis entre universitários. Ciênc Saúde Colet [Internet]. 2016 [acesso em 2016 set 26];21(6):1975-84. Disponível em: http://www.scielo.br/pdf/csc/v21n6/1413-8123-csc-21-06-1975.pdf.

7. Costa RF, Queiroz MVO, Zeitoune RCG. Cuidado aos adolescentes na atenção primária: perspectivas de integralidade. Esc Anna Nery Rev Enferm [Internet]. 2012 jul-set [acesso em 2016 set 26];16(3):466-72. Disponível em: http://www.scielo.br/scielo.php?script=sci_arttext\&pid=S1414-81452012000300006.

8. Brasil. Ministério da Saúde. Secretaria de Vigilância em Saúde. Departamento Nacional de DST, Aids e Hepatites Virais. Pesquisa de conhecimentos, atitudes e práticas na população brasileira 2008. Brasília (DF): Ministério da Saúde; 2011.

9. Bezerra EO, Chaves ACP, Pereira MLD, Melo FRG. Análise da vulnerabilidade sexual de estudantes universitários ao HIV/aids. Rev RENE [Internet]. 2012 [acesso em 2016 set 26];13(5):1121-31. Disponível http://www.periodicos.ufc.br/index.php/rene/article/view/4118/3209.

em:

10. D'Amaral HB, Rosa LA, Wilken RO, Spindola T, Pimentel MRRA, Ferreira LEM. As práticas sexuais dos graduandos de enfermagem e a prevenção das doenças sexualmente transmissíveis. Rev Enferm UERJ [Internet]. 2015 [acesso em 2016 set 26];23(4):494-500. Disponivel em: http://www.facenf.uerj.br/v23n4/v23n4a10.pdf.

11. Borges MR, Silveira RE, Santos AS, Lippi UG. Comportamento sexual de ingressantes universitários. Rev Pesqui Cuid Fundam[Internet]. 2015 [acesso em 2016 set 26];7(2):250515.

Disponivel

em:

http://www.seer.unirio.br/index.php/cuidadofundamental/article/view/3676/pdf_1588.

12. Gomes VLO, Amarijo CL, Baumgarten LZ, Arejano CB, Fonseca AD, TomaschewskiBarlem JG. Vulnerabilidade de estudantes de enfermagem e medicina pela ingestão de bebidas alcoólicas. Rev Enferm UFPE [Internet]. 2013 [acesso em 2016 set 26];7(1):128-34. Disponivel

em: http://www.revista.ufpe.br/revistaenfermagem/index.php/revista/article/view/2925/pdf_1850.

13. Sousa TF, José HPM, Barbosa AR. Condutas negativas à saúde em estudantes universitários brasileiros. Ciênc Saúde Colet [Internet]. 2013 [acesso em 2016 set 26];18(12): 3563-75. Disponível em: http://www.scielo.br/scielo.php?script=sci_arttext\&pid=S141381232013001200013. 


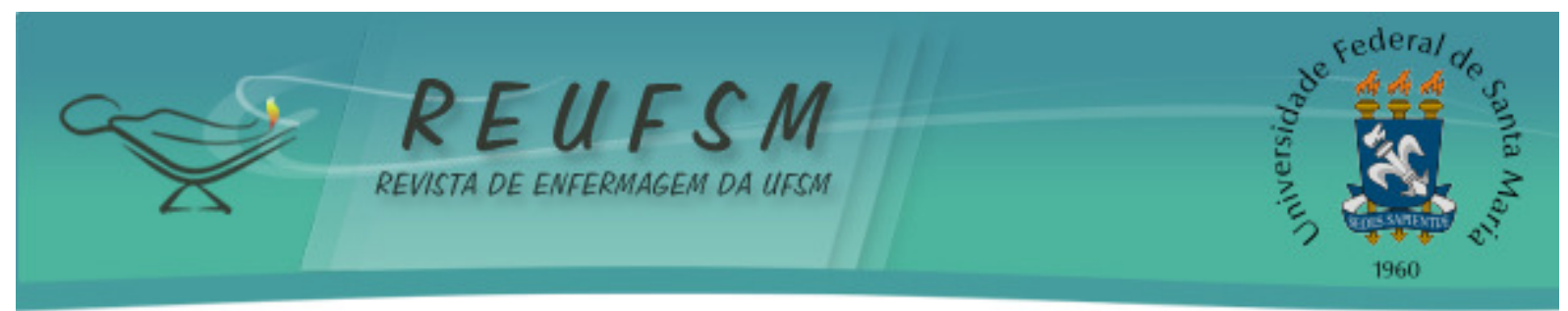

14. Mello MVO, Bernardelli Junior R, Menossi BRS, Vieira FSF. Comportamento de risco para a saúde de estudantes da Universidade Estadual do Norte do Paraná (Brasil) - uma proposta de intervenção online. Ciênc Saúde Colet [Internet]. 2014 [acesso em 2016 set 26]; 19(1):159-64. Disponível em: http://www.scielo.br/scielo.php?script=sci_arttext\&pid=S141381232014000100159.

15. Rodríguez DEC, Varela YP. Percepciones que afectan negativamente el uso del condón en universitarios de la costa Caribe Colombiana. Hacia Promoc Salud [Internet]. 2014 [acesso em 2016 set 26];19(1):54-67. Disponível em: http://www.scielo.org.co/pdf/hpsal/v19n1/v19n1a05.pdf.

16. Baumgarten LZ, Gomes VLO, Fonseca AD. Consumo alcoólico entre universitários(as) da área da saúde da Universidade Federal do Rio Grande/RS: subsídios para enfermagem. Esc Anna Nery Rev Enferm [Internet]. 2012 [acesso em 2016 set 26];16(3):530-5. Disponível em: http://www.scielo.br/pdf/ean/v16n3/15.pdf.

17. Reis M, Ramiro L, Matos MG, Diniz JÁ. Os comportamentos sexuais dos universitários portugueses de ambos os sexos em 2010. Rev Port Saúde Pública [Internet]. 2012 [acesso em 2016 set 26];30(2):105-14. Disponível em: http://www.scielo.mec.pt/pdf/rpsp/v30n2/v30n2a02.pdf.

18. Estupiñan-Aponte MR, Amaya-Estupiñán LC, Rojas-Jiménez Y.A. Representaciones sociales de universitarios sobre la abstinência sexual y los condones como mecanismo de prevención. Rev Salud Pública [Internet]. 2012 [acesso em 2016 set 26];14(3):491-501. Disponivel em: http://www.scielosp.org/scielo.php?script=sci_arttext\&pid=S012400642012000300012.

19. Rodríguez-Gázquez MA, Chaparro-Hernández S, González-López JR. Lifestyles of nursing students from a Colombian public university. Invest Educ Enferm [Internet]. 2016 [acesso em 2016 set 26];34(1):94-103. Disponível em: https://aprendeenlinea.udea.edu.co/revistas/index.php/iee/article/view/25993/20779902.

20. Joint United Nations Programe on HIV/AIDS (UNAIDS). 90-90-90: An ambitious treatment target to help end the AIDS epidemic [Internet]. Geneva: UNAIDS; 2014 [acesso em 2016 set 26]. Disponível em: http://www.unaids.org/sites/default/files/media_asset/90-9090_en_0.pdf.

Data de submissão: 30/01/2017

Data de aceite: $21 / 09 / 2017$

Autor correspondente: Thelma Spindola

Endereço: Boulevard 28 de Setembro, 157 - Vila Isabel, Rio de Janeiro - RJ, Brasil.

CEP: 20551-030

Email: tspindola.uerj@gmail.com 